\title{
Relationship Between Parental Big Five And Children's Ability To Delay Gratification
}

\author{
Pauline S. Effenberger ${ }^{1} \cdot$ Fabian Streit $^{2} \cdot$ Svenja Bardtke ${ }^{1} \cdot$ Maria Gilles $^{1} \cdot$ Isabell A.-C. Wolf $^{1} \cdot$ Annette Schröder $^{3}$.

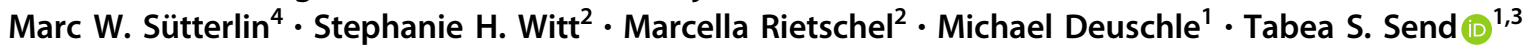

Accepted: 22 November 2021 / Published online: 14 December 2021

(c) The Author(s) 2021

\begin{abstract}
The ability to delay gratification is related to success in school and other aspects of life. Genetic as well as environmental factors such as parenting style partly explain the development of delay of gratification (DoG). However, it is unclear whether parental personality impacts children's DoG, and how maternal and paternal personalities contribute to this relationship. The present study investigates the relationship between parental personality and 45-month-old children's DoG $(N=329)$. Personality was measured using the NEO-Five-Factor-Inventory-30, DoG was operationalized through waiting time in the marshmallow test. In model 1 , using only maternal data to predict DoG, maternal openness to experience was associated with shorter waiting time of the child in the marshmallow test, whereas maternal agreeableness was associated with longer waiting time. In model 2, using only paternal data to predict DoG, paternal agreeableness was related to longer waiting time. In model 3, combining maternal and paternal data to predict DoG, maternal openness to experience as well as paternal agreeableness remained significant predictors of DoG. The present study underlines the influence of both parents' personalities on the development of children's DoG and indicates differential maternal and paternal effects. Future studies should investigate the relationship between parental personality and children's DoG in detail and take further factors into account, such as genetic factors, other environmental factors and the personality of the child.
\end{abstract}

Keywords Delay of gratification $\cdot$ Marshmallow test $\cdot$ Children $\cdot$ Maternal personality $\cdot$ Paternal personality $\cdot$ Big Five

\section{Highlights}

- Investigation of parental personality jointly and separately to predict child's DoG.

- Separate models: Agreeableness of both parents predicts DoG (positively).

- Separate models: Maternal openness predicts DoG (negatively).

- Joint model: Maternal openness \& paternal agreeableness stay significant predictors.

- The results indicate differential maternal and paternal effects on children's DoG.

Supplementary information The online version contains supplementary material available at https://doi.org/10.1007/s10826021-02196-8.

Tabea S. Send

tabea.send@zi-mannheim.de

1 Department of Psychiatry and Psychotherapy, Central Institute of Mental Health, Medical Faculty Mannheim, University of Heidelberg, J5, 68159 Mannheim, Germany

2 Department of Genetic Epidemiology in Psychiatry, Central Institute of Mental Health, Medical Faculty Mannheim, University
The ability to delay gratification is crucial for success across the life span and its implications have been studied extensively. Several studies associate delay of gratification (DoG) at as early as preschool age with success later in life, including higher cognitive and academic performance as

\section{of Heidelberg, J5, 68159 Mannheim, Germany}

3 Department of Clinical Psychology and Psychotherapy, University of Koblenz-Landau, Ostbahnstraße 10, 76829 Landau, Germany

4 Department of Gynecology and Obstetrics, University Medical Center Mannheim, University of Heidelberg, Theodor-Kutzer-Ufer 1-3, 68167 Mannheim, Germany 
well as higher ability to deal with stress and frustration (Mischel et al. 1988; Shoda et al. 1990). In addition, a child's self-control, which is correlated with DoG (Duckworth et al. 2013), predicts prosperity and health in adulthood (Fergusson et al. 2013; Moffitt et al. 2011).

Despite extensive research about the ability to delay gratification, there is still a need to identify the factors that contribute to the development of DoG. A twin study showed that genetic factors influence the preference to discount the value of a larger, delayed versus a smaller, immediate reward (delay discounting), observing an estimated heritability of delay discounting around $40 \%$ at age 16 and around 60\% at age 18 (Anokhin et al. 2015). Recently, a genome-wide association study identified genetic variants involved in delay discounting (SanchezRoige et al. 2018). Besides genetic variants accounting for variance in delay discounting, environmental factors influencing the development of DoG are also of great interest.

The environment of younger children is largely dominated by their parents: Parents can influence their children's behavior e.g. via acting as a role model in the sense of observational learning (Bandura 1986), by actively reinforcing or punishing children's behavior, or by providing a stimulating environment (Gottfried et al. 1998). Parental behavior is influenced by parental personality (Edwards 2015; Prinzie et al. 2005; Prinzie et al. 2009), and therefore, it can be expected that parents' personality can have an influence on the child by affecting their own behavior and thus determining a relevant part of children's environmental influence. The most established personality model is the Big Five model, which is derived from factor analyses and consists of the five factors Neuroticism, Extraversion, Openness to experience, Agreeableness, and Conscientiousness (McCrae and Costa 1987). Parental extraversion, openness to experience, agreeableness as well as conscientiousness are associated with positive parenting behavior such as warmth/sensitivity and behavioral control (Edwards 2015; Prinzie et al. 2009). A negative relationship was found between parental neuroticism and positive educational behavior (Prinzie et al. 2009). Overreactivity, a negative parenting behavior, is negatively associated with parental agreeableness and conscientiousness (Prinzie et al. 2005). Furthermore, an association has been demonstrated between parenting practices and children's ability to self-regulate (Edwards 2015; Karreman et al. 2006). For example, positive parenting (e.g., autonomy support, warmth/sensitivity, guidance) favors children's ability with regard to executive function, effortful control, and self-regulation (Bindman et al. 2015; Edwards 2015; Karreman et al. 2006), whereas negative parenting (e.g., overcontrolling behavior, negativity) is associated with aspects of low self-regulation (Karreman et al. 2006). Additionally, maternal sensitivity has been linked to children's development of DoG (Razza and Raymond 2013).

Therefore, parental personality factors represent a promising approach to investigate differences in the development of DoG and related concepts such as effortful control and self-control (Duckworth et al. 2013; Li-Grining 2007). Parental personality is directly linked to effortful control in children: extraversion of both parents is positively, and paternal neuroticism is negatively associated with children's parent-rated effortful control at five and a half years (Komsi et al. 2008). Furthermore, externalizing problem behavior, which is marked by lower effortful regulation, higher impulsivity (Eisenberg et al. 2005), and lower DoG in children (Krueger et al. 1996), has also been linked to different parental personality factors. Externalizing problem behavior in children has been associated with high maternal neuroticism and low maternal conscientiousness (Nigg and Hinshaw 1998; Prinzie et al. 2005). However, findings regarding maternal agreeableness are not entirely consistent (Nigg \& Hinshaw 1998; Prinzie et al. 2004, 2005). With regard to the father's personality, children's externalizing problem behavior has been associated with low paternal agreeableness and extraversion (Prinzie et al. 2004, 2005).

To our knowledge, the relationship between maternal personality and children's DoG has only been addressed in one study so far: In a sample of six-year-old school children, Drobetz et al. (2012) measured maternal personality with the Big Five Inventory-SOEP (BFI-S) and DoG with the DoG paradigm by Mischel et al. (1989). In this study no relationship between maternal Big Five and children's DoG was found. However, this research question has not been extended to include paternal personality to date. Mothers are often the primary caregiver of the child, and in the sense of pre-, peri- and early postnatal influences, they are also biologically linked more closely to their child. Therefore, research on parental influences on younger children often focusses on the mothers. However, research indicates, that also the father is of importance and paternal effects can differ from maternal ones (Lewis and Lamb 2003). Additionally, it can be expected that the personality of one parent is not completely independent from the personality of the other parent, e.g. because of assortative mating (Escorial and Martin-Buro 2012) or co-development (Allemand and Martin 2016). Thus, to assess the influence of one parent it is important to adjust for the personality of the other parent.

Investigating the relationship of parents' personality and children's DoG is important for a better understanding of the development of DoG and therefore essential for developing interventions to improve DoG in children. Since it is difficult to influence personality, it will be relevant for future research to identify mediators of this association, i.e., specific parental behavior, which can be influenced or trained in order to improve children's DoG. The present 
study aims to explore how the ability to delay gratification develops in the context of maternal personality and to extend the scope of environmental influence by also investigating the impact of paternal personality. We did not postulate specific hypotheses for single Big Five traits, and analyzed the associations of the Big Five with children's DoG in an exploratory way. However, we had certain expectations for the results: As the mothers in the present sample reported more often to be the main caregiver of the child and therefore were likely the parent spending more time with the child on average, we expected a stronger association between maternal personality and children's DoG. Additionally, in regard to the potentially specific differences of maternal and paternal effects, we expected to observe differences in the association of fathers' and mothers' Big Five and children's DoG (Lewis and Lamb 2003). Of note, the influence of maternal and paternal personality was assessed separately, but also analyzed together in a joint model to adjust for the personality of the other parent, and rule out effects of assortative mating (Escorial and Martin-Buro 2012) or co-development (Allemand and Martin 2016). Aim 1 was to test the association of maternal personality with children's DoG, Aim 2 was to test the association of paternal personality with children's DoG and Aim 3 was to test the association of both parents' personality on children's DoG simultaneously in a joint model.

\section{Methods}

\section{Study Design and Sample}

The present work is part of the study "POSEIDON" (Pre-, Peri- and Postnatal Stress: Epigenetic Impact on Depression) which investigates maternal stress during pregnancy and children's development and health. The sample consists of 410 women and their children. Recruiting of the sample took place in the Rhine-Neckar region of Germany from October 2010 to March 2013. For more details on the sample and the recruiting process, see Send et al. (2017) and Wolf et al. (2017). To answer our research question, data from the study waves T1 (during pregnancy), T3 (6 months post partum) and T4 (45 months post partum) were analyzed. Only subjects of the POSEIDON cohort who participated in both waves $\mathrm{T} 1$ and $\mathrm{T} 4$ were included in the analyses. At T1, German-speaking pregnant women between 16 and 45 years of age who would presumably also be the main caregiver of the child after birth were included in the study. Women were excluded from the study if they had any current psychiatric disorder which required inpatient treatment or any current or past diagnosis of a psychotic disorder or schizophrenia, any substance dependency during pregnancy other than nicotine, positive human immunodeficiency virus, or hepatitis B or C status. Participants were also excluded from the study if the newborn was born before the 30th week of pregnancy, weighed $<1500$ grams at birth, was part of a multiple birth, or had any congenital disease, deformation, malformation, and/or chromosomal abnormality.

302 mothers and their children of the original POSEIDON cohort participated at T4. To maintain the original sample size of approximately 400 mother-child-dyads, we replaced the $\sim 100$ dropouts. For this purpose, parents of 45-month-old children were contacted using information from the local resident registries of two German cities. The criteria for participation were assessed based on screening questionnaires. All families who met the criteria were invited to the study, and a total of 101 new dyads participated at T4. Multiple birth led to exclusion only in the original POSEIDON sample, and four twin pairs participated in the new sample. In sum, with 302 mothers and their children from the original POSEIDON cohort and 101 from the new cohort, the sample at T4 consisted of 403 participants. For more details on the new subsample and the recruiting process, see Send et al. (2019).

The study was conducted following the Declaration of Helsinki. The ethics committee of a German university approved the study protocol. All participants provided written informed consent before they participated in the study.

\section{Materials}

NEO-five factor inventory 30 -item short version (NEO-FFI30)

The NEO-FFI-30, developed and evaluated by Körner et al. (2008), is a German-language self-report questionnaire used for the economic measurement of the five basic personality dimensions called the Big Five, which include neuroticism, extraversion, openness to experience, agreeableness, and conscientiousness. Every personality dimension is measured by six items. The items are rated on a five-point Likert scale $(0=$ strongly disagree, $4=$ strongly agree $)$.

The NEO-FFI-30 was conducted in a paper-pencilformat. The mothers of the POSEIDON cohort completed it at $\mathrm{T} 1$, the fathers at $\mathrm{T} 3$; the mothers and fathers of the newly recruited subsample completed it at $\mathrm{T} 4$. In the present sample, the internal consistencies for the single scales of the NEO-FFI-30 for the mothers were Cronbach's $\alpha=0.79$ for neuroticism, Cronbach's $\alpha=0.60$ for extraversion, Cronbach's $\alpha=0.76$ for openness to experience, Cronbach's $\alpha=0.70$ for agreeableness, and Cronbach's $\alpha=0.70$ for conscientiousness. For the fathers, the internal consistencies were Cronbach's $\alpha=0.78$ for neuroticism, Cronbach's 
$\alpha=0.70$ for extraversion, Cronbach's $\alpha=0.74$ for openness to experience, Cronbach's $\alpha=0.70$ for agreeableness, and Cronbach's $\alpha=0.70$ for conscientiousness.

\section{Procedure}

\section{Delay of gratification paradigm}

The delay of gratification paradigm developed by Mischel and Ebbesen (1970) measures the ability of a child to delay gratification. A modified version of this paradigm was conducted in this study at T4. All children chose one of three types of sweets (a piece of chocolate, a large gummy bear, or a biscuit). The child was instructed that it could either eat the sweet immediately or wait to eat it and get a second sweet. If the child chose to wait, it was told to sit on its chair and wait until the researcher entered the room again without being called by the child. While waiting, the child was alone in the room and sat at a table on which the sweet was placed. The researcher and the mother watched the child from another room through a video camera hidden in the waiting room. The child was also told that it could call its mother at any time to come back, but that this would lead to just one sweet. The mother was informed that she could interrupt the test at any time if she had the impression that her child was not feeling well. The waiting time was measured in minutes, and the maximum waiting time after which the researcher returned to the room was twelve minutes. In case the child called the researcher or the mother, the marshmallow test was ended, and the time at which the child called was counted as the end of the waiting period.

\section{Statistical Analysis}

Statistical analyses were conducted using IBM SPSS ${ }^{\oplus}$ Statistics (Version 25). In total, 403 children and their mothers participated at T4. 74 parent-child triads were excluded from the statistical analyses: 33 participants with their children were not included in the analyses because the NEO-FFI-30 of the mother was missing completely or partially (9) or because the delay of gratification paradigm could not be performed (24). Eight triads were excluded because the child needed to go to the restroom during the delay paradigm. Another 25 parent-child triads were not included in the analyses because the researcher had to enter the room during the delay paradigm, e.g., because the child stood up and was no longer visible through the hidden camera. It is unclear whether these children would have waited without the short contact with the researcher. Furthermore, eight triads were excluded as either the child had obviously not understood the instruction (2), the parents vehemently instructed the child and entered the room during the delay situation (1), the mother asked to end the delay paradigm (2), or the paradigm had to be performed with an open door due to technical reasons (3). In total, $N=329$ mothers with their children were included in statistical analyses using only mother data. Of these $N=329$ participants, only $n=267$ had complete father data. Therefore, analyses using only father data or both, mother and father data, include only $n=267$ participants. For descriptive statistical analysis, average values and standard deviations were calculated. Product-moment-correlations by Pearson were calculated for all variables. As gender differences in DoG might exist across different age levels (Silverman 2003), a $t$-test for independent samples was conducted to investigate whether waiting time differed between the sexes. As known factors associated with DoG, we included parental education (Bindman et al. 2015; Razza and Raymond 2013) as a measure of socioeconomic status and children's age (Drobetz et al. 2012; Houck and Lecuyer-Maus 2004) as control variables in our models. The variable years of education was defined as the sum of years a subject spent in school, university, and vocational training and was used as a continuous measure of socioeconomic status.

Three multiple linear regression models were calculated to evaluate the association between the parental personality dimensions and the children's waiting time in minutes as the dependent variable according to Aims 1-3 of the present study: Aim 1 was tested with a model including maternal Big Five and maternal education, aim 2 was tested with a model including paternal Big Five and paternal education, and aim 3 was tested with a model combining Big Five and education of the mother and the father simultaneously. All models controlled for the children's age. Since the residuals of the dependent variable were not normally distributed, the distribution of the residuals and the computed regression parameters were estimated by 1000 random draws of smaller samples from the given sample using bootstrapping, and the unstandardized regression parameter $\mathrm{B}$ was considered significant if its $95 \%$ confidence interval did not include zero.

\section{Results}

In total, $N=329$ mothers with their children were included in statistical analyses using only maternal variables. Due to missing values, paternal variables were only available for $n=267$. Therefore, the number of parentchild triads differed between analyses that included any of these variables. Table 1 provides demographic data of parents and children at T4. The children's average age was $M=45.0$ months and ranged from a minimum age of 43 months to a maximum of 49 months. $52.6 \%$ of the children were female. 
Table 1 Demographic data of subjects included in the analyses

Maternal years of education

$M$ (SD)

$14.66(2.29)$

Paternal years of education ${ }^{\mathrm{a}}$

$M$ (SD)

$14.75(2.20)$

Children's age in months

$M$ (SD)

$45.0(1.01)$

Children's sex

Female

$173(52.6 \%)$

Male

$156(47.4 \%)$

$N=329$

${ }^{\mathrm{a}} n=267$

The means, standard deviations, and correlations of all variables included in the following analyses are shown in Supplementary Table S1, the distribution of the waiting time is depicted in Supplementary Fig. S2. The age of the child as well as the years of education of the mother and the father show significant positive correlations with the waiting time. Therefore, they were included as control variables in the following analyses.

No significant difference in waiting time between girls $(M=5.05, \mathrm{SD}=5.08)$ and boys $(M=5.67, \mathrm{SD}=5.01)$ could be found $(t(327)=-1.11, p=0.27)$. Thus, sex was not included as a control variable in the following analyses.

\section{Aim 1 (Maternal Personality)}

The model predicting the children's waiting time with the five maternal personality traits, the children's age, and the mothers' education $(n=329)$ explained $8.3 \%$ of the variance in waiting time $(F(7,321)=4.15, p=0.00022$, $R^{2}=0.083$ ).

Table 2 shows the regression parameters of each predictor and the constant estimated by bootstrapping. A significant negative association was observed between maternal openness to experience and the children's waiting time $(B=-1.04 ; p=0.0090)$. Furthermore, a significant positive association between maternal agreeableness and the children's waiting time could be identified $(B=0.97$; $p=0.035)$. The children's age $(B=0.70 ; p=0.017)$ and years of maternal education $(B=0.49 ; p=0.0020)$ were both significantly positively associated with the children's waiting time.

\section{Aim 2 (Paternal Personality)}

The model predicting the children's waiting time through the fathers' five personality traits, the children's age, and the fathers' education $(n=267)$ explained $7.4 \%$ of the variance of waiting time $\left(F(7,259)=2.96, p=0.0053, R^{2}=0.074\right)$.
Table 3 shows the regression parameters of each predictor and the constant estimated by bootstrapping. A significant positive association between paternal agreeableness and the children's waiting time $(B=1.10 ; p=0.030)$ was observed. The years of paternal education $(B=0.34 ; p=$ 0.020 ) were significantly positive associated with the waiting time of the child. A marginally significant positive association was observed between children's age and children's waiting time $(B=0.57 ; p=0.083)$.

\section{Aim 3 (Maternal and Paternal Personality)}

The model predicting the child's waiting time through the five personality traits of both the mother and father, the children's age, and maternal as well as paternal education ( $n=267$ ) explained $11.7 \%$ of the variance of the waiting time $(F(13,253)=2.57, p=0.0024)$.

Table 4 shows the regression parameters of each predictor and the constant estimated by bootstrapping. A significant negative association between maternal openness to experience and the children's waiting time

$(B=-1.15 ; p=0.013)$ was observed. The positive association between maternal agreeableness and the children's waiting time was marginally significant in this model $(B=1.05 ; p=0.076)$. Regarding the paternal personality traits, a significant positive association was observed between paternal agreeableness and the children's waiting time $(B=0.99 ; p=0.033)$. The children's age $(B=0.63$; $p=0.052$ ) showed a marginally significant positive association with the children's waiting time.

\section{Discussion}

The present work aimed to explore the association between parental personality and children's DoG in the marshmallow test at the age of 45 months. We tested whether maternal and paternal neuroticism, extraversion, openness to experience, agreeableness and conscientiousness are related to children's DoG. The influence of maternal and paternal personality was analyzed both in two separate models and together in a joint model. Aims 1 and 2 tested the association of maternal respectively paternal personality with children's DoG separately, whereas aim 3 tested the influence of both parents' personality on children's DoG simultaneously in a joint model. Maternal openness to experience was negatively associated with the children's waiting time in both models including maternal data (Aims 1 and 3). Additionally, a positive association between maternal agreeableness and children's waiting time was shown in the model including only maternal data (Aim 1). In the combined model, this positive association was only marginally significant. However, the effect size was similar 
Table 2 Parameter estimation by bootstrapping of model 1 (maternal)

\begin{tabular}{|c|c|c|c|c|c|c|c|}
\hline & \multirow[b]{2}{*}{$B^{\mathrm{a}}$} & \multirow[b]{2}{*}{ Beta $^{b}$} & \multicolumn{2}{|c|}{ 95\% Confidence interval } & \multirow[b]{2}{*}{ Bias $^{\mathrm{c}}$} & \multirow[b]{2}{*}{$\mathrm{SE}^{\mathrm{d}}$} & \multirow[b]{2}{*}{$p$} \\
\hline & & & Lower limit & Upper limit & & & \\
\hline Constant & $-31.12 *$ & & -56.19 & -4.86 & 0.11 & 12.99 & 0.018 \\
\hline Neuroticism, mother & 0.21 & 0.033 & -0.68 & 1.12 & -0.0017 & 0.46 & 0.64 \\
\hline Extraversion, mother & -0.57 & -0.061 & -1.56 & 0.43 & 0.0026 & 0.51 & 0.26 \\
\hline Openness, mother & $-1.04 * *$ & -0.16 & -1.76 & -0.28 & 0.012 & 0.38 & 0.0090 \\
\hline Agreeableness, mother & $0.97 *$ & 0.13 & 0.094 & 1.88 & 0.0028 & 0.46 & 0.035 \\
\hline Conscientiousness, mother & -0.65 & -0.079 & -1.71 & 0.37 & 0.00032 & 0.52 & 0.20 \\
\hline Age of the child & $0.70^{*}$ & 0.14 & 0.15 & 1.25 & -0.0043 & 0.28 & 0.017 \\
\hline Years of education, mother & $0.49 * *$ & 0.22 & 0.23 & 0.76 & 0.0025 & 0.13 & 0.0020 \\
\hline \multicolumn{8}{|c|}{$* * p<0.01 ; * p<0.05$ (two-sided), $N=329$} \\
\hline \multicolumn{8}{|c|}{ âNon-standardized regression coefficient } \\
\hline \multicolumn{8}{|c|}{${ }^{\mathrm{b}}$ Not estimated by bootstrapping } \\
\hline
\end{tabular}

in both models. Paternal agreeableness was positively associated with the children's waiting time in both models including paternal data (Aim 2 and 3).

The positive association between parental agreeableness and children's waiting time could be explained by the relation that parents with higher agreeableness might be more responsive to their children's needs. Maternal responsiveness is associated with greater effortful control of the child (Kochanska et al. 2000), and similar associations might exist for fathers. Moreover, parental agreeableness is positively associated with specific parenting behavior (i.e., warmth, behavioral control, autonomy support; Prinzie et al. 2009) conducive to children's executive function, effortful control, and self-regulation (Bindman et al. 2015; Edwards 2015; Karreman et al. 2006). This effect was observed for both fathers and mothers, and the comparable effect sizes in the joint model indicate an effect largely independent of the other parent, making it unlikely that the observed effects in the fathers merely reflects assortative mating (Escorial and Martin-Buro 2012) or codevelopment (Allemand and Martin 2016). The shorter waiting time of children whose mothers are more open to experience could possibly be related to the larger number of novel environmental stimuli these children experience in everyday life. Since openness to experience is related to creativity (McCrae 1987) and sensation seeking (Roberti 2004), more open mothers might think and act flexibly as well as seek varied and novel experiences, thereby creating a varied environment for them and their children. In comparison to the children of mothers with lower values in openness, it may be more difficult for them to wait in a low-stimulus room. We did not observe this effect in the fathers. This is in line with the assumption, that maternal and paternal effects on the offspring might differ in their exact nature (Lewis and Lamb 2003).
To our knowledge, the relationship between maternal personality and children's DoG has only been addressed in one study so far: In a sample of six-year-old school children, Drobetz et al. (2012) measured maternal personality with the Big Five Inventory-SOEP (BFI-S) and DoG with the delay of gratification paradigm by Mischel et al. (1989). In this sample, no associations between maternal Big Five and the children's DoG were found. However, methodological differences between the studies may have contributed to these results. For example, DoG was recorded dichotomously (Delayer versus Non-Delayer) by Drobetz et al. (2012). With an average age of 72 months, the children were relatively old for the delay of gratification paradigm and a high percentage of delayers $(78.3 \%)$ was observed. These differences may have contributed to the null effect regarding the relationship between maternal personality and children's DoG in the study of Drobetz et al. (2012).

In the present study, the age of the child showed a positive association with waiting time in the marshmallow test. This is consistent with previous findings of positive associations between children's age and DoG showing an increase of children's ability to delay gratification over development (Drobetz et al. 2012; Houck and LecuyerMaus 2004). Maternal and paternal years of education were also significantly associated with children's waiting time in the models including only maternal and paternal data, respectively. This is in line with previous studies showing associations of maternal education with children's DoG (Bindman et al. 2015; Razza and Raymond 2013). Therefore, a higher educational level of the parents could potentially contribute to an environment favoring the development of children's DoG. However, it must be noted that these associations did not remain significant in the combined model. No gender differences in the waiting time were found in the present study, which is consistent with the 
Table 3 Parameter estimation by bootstrapping of model 2 (paternal)

\begin{tabular}{|c|c|c|c|c|c|c|c|}
\hline & \multirow[b]{2}{*}{$B^{\mathrm{a}}$} & \multirow[b]{2}{*}{ Beta $^{b}$} & \multicolumn{2}{|c|}{ 95\% Confidence interval } & \multirow[b]{2}{*}{ Bias $^{c}$} & \multirow[b]{2}{*}{$\mathrm{SE}^{\mathrm{d}}$} & \multirow[b]{2}{*}{$p$} \\
\hline & & & Lower limit & Upper limit & & & \\
\hline Constant & $-2.99 *$ & & -62.53 & -3.30 & 0.013 & 15.19 & 0.033 \\
\hline Neuroticism, father & 0.46 & 0.059 & -0.58 & 1.57 & -0.00074 & 0.56 & 0.41 \\
\hline Extraversion, father & 0.30 & 0.036 & -0.94 & 1.43 & -0.034 & 0.58 & 0.58 \\
\hline Openness, father & 0.54 & 0.079 & -0.31 & 1.40 & 0.039 & 0.45 & 0.25 \\
\hline Agreeableness, father & $1.10 *$ & 0.14 & 0.15 & 2.04 & 0.013 & 0.47 & 0.030 \\
\hline Conscientiousness, father & 0.77 & 0.084 & -0.51 & 2.08 & 0.0052 & 0.64 & 0.23 \\
\hline Age of the child & $0.57^{+}$ & 0.11 & -0.091 & 1.22 & -0.0023 & 0.33 & 0.083 \\
\hline Years of education, father & $0.34 *$ & 0.15 & 0.058 & 0.64 & 0.0014 & 0.15 & 0.020 \\
\hline \multicolumn{8}{|c|}{${ }^{* *} p<0.01 ; * p<0.05 ;{ }^{+} p<0.10$ (two-sided), $n=267$} \\
\hline \multicolumn{8}{|c|}{${ }^{a}$ Non-standardized regression coefficient } \\
\hline \multicolumn{8}{|c|}{${ }^{\mathrm{b}}$ Not estimated by bootstrapping } \\
\hline
\end{tabular}

findings of Mittal et al. (2012) in a sample of 2- and 3-yearold children. On the other hand, a meta-analysis including people of all ages conducted by Silverman (2003) found small gender differences in DoG across different age levels, including preschoolers, tending to a small advantage of girls and women. More research is needed to clarify the influence of gender on DoG in preschoolers.

Models 1 and 2 explain quite a similar amount of variance in waiting time $(8.3 \%$ for maternal personality and $7.4 \%$ for paternal personality). This is especially interesting since only $49.2 \%$ of the mothers in our sample stated that they fully share the responsibility for the care and education of their child with the father. That means, although more than half of the mothers in our sample report to take more responsibility than the father and thus have probably more interaction with the child, the influence of paternal personality almost equals the influence of maternal personality regarding DoG. Those results do not strongly support our expectation to find stronger effects in the mothers. However, it has to be noted, that in the mothers two of the Big Five were significantly associated with the children's DoG, while in the fathers, only agreeableness was significantly associated. Our results indicate that future research should not only concentrate on the influence of the mother but should consider the influence of the father with equal weight even if the mother might be the main caregiver. The combined model including both parents' personalities explains $11.7 \%$ of the variance of the children's DoG, indicating an independent contribution of mothers and fathers personality.

There are several limitations of this study. First, the mothers of the POSEIDON cohort completed the NEOFFI-30 at $\mathrm{T} 1$ and the fathers completed it at T3, whereas the newly recruited subsample (about a quarter of the participants) completed it at T4. However, the five investigated personality traits show moderate to high stability over a period of nine years (Rantanen et al. 2007). Therefore, we assumed no systematic differences between the different times of data collection. Second, some scales of the NEO-FFI-30 show a limited internal consistency in this sample. Third, the children in the present study were about three years and nine months old. The marshmallow test by Mischel and Ebbesen (1970) can be considered the golden standard for measuring DoG during childhood. However, children in the original study of Mischel were about four and a half years old (Mischel et al. 1972; Mischel and Ebbesen 1970). Since the children in the present study were younger, the results of the marshmallow test might have been influenced more strongly by other factors, e.g., by how long the child can be separated from its mother. Fourth, we were only able to evaluate the children's DoG at one age to date. It would be useful to measure DoG at a later point of the study using a test that is appropriate for the children's respective age and that is potentially related to outcomes such as school performance. Fifth, genetic and further environmental factors possibly influencing DoG as well as their interactions were not accounted for in the present study, and associations between the parents' personalities and the children's DoG might have been mediated by a shared genetic disposition. Sixth, as this study only took place in Germany using a German-speaking sample, results are limited regarding cultural aspects and therefore cannot be generalized to other cultures. Future studies are needed to investigate this research question in other cultures.

A better understanding of how DoG develops would open up opportunities to support children with a low ability to delay gratification. Previous research has shown that early DoG and self-control in children are associated with subsequent success, such as higher cognitive competence 
Table 4 Parameter estimation by bootstrapping of model 3 (maternal and paternal)
95\% Confidence interval

\begin{tabular}{lccccccc}
\cline { 6 - 7 } & $B^{\mathrm{a}}$ & Beta $^{\mathrm{b}}$ & Lower limit & Upper limit & Bias $^{\mathrm{c}}$ & $\mathrm{SE}^{\mathrm{d}}$ & $p$ \\
\hline Constant & $-38.24^{*}$ & & -69.49 & -8.64 & -0.87 & 15.12 & 0.012 \\
Neuroticism, mother & 0.63 & 0.093 & -0.49 & 1.73 & -0.015 & 0.56 & 0.24 \\
Extraversion, mother & -0.17 & -0.017 & -1.51 & 1.12 & -0.0048 & 0.64 & 0.78 \\
Openness, mother & $-1.15^{*}$ & -0.14 & -2.08 & -0.33 & -0.019 & 0.45 & 0.013 \\
Agreeableness, mother & $1.05^{+}$ & 0.13 & -0.12 & 2.12 & -0.015 & 0.58 & 0.076 \\
Conscientiousness, mother & -0.65 & -0.077 & -1.80 & 0.52 & 0.017 & 0.59 & 0.27 \\
Neuroticism, father & 0.53 & 0.068 & -0.58 & 1.71 & 0.021 & 0.59 & 0.38 \\
Extraversion, father & 0.29 & 0.034 & -0.93 & 1.36 & -0.031 & 0.60 & 0.65 \\
Openness, father & 0.72 & 0.11 & -0.077 & 1.59 & 0.020 & 0.43 & 0.11 \\
Agreeableness, father & $0.99^{*}$ & 0.12 & 0.064 & 1.93 & 0.041 & 0.47 & 0.033 \\
Conscientiousness, father & $1.11^{+}$ & 0.12 & -0.070 & 2.33 & 0.024 & 0.60 & 0.069 \\
Age of the child & $0.63^{+}$ & 0.13 & 0.014 & 1.29 & 0.014 & 0.32 & 0.052 \\
Years of education, mother & 0.25 & 0.11 & -0.19 & 0.68 & -0.00095 & 0.22 & 0.26 \\
Years of education, father & 0.24 & 0.11 & -0.12 & 0.63 & 0.010 & 0.18 & 0.18 \\
\hline
\end{tabular}

$* * p<0.01 ; * p<0.05 ;{ }^{+} p<0.10$ (two-sided), $n=267$

${ }^{a}$ Non-standardized regression coefficient

${ }^{\mathrm{b}}$ Not estimated by bootstrapping

${ }^{c}$ Difference between sample mean and bootstrapped mean of the variable

${ }^{\mathrm{d}}$ Standard errors
(Mischel et al. 1988; Shoda et al. 1990) and prosperity in adulthood (Fergusson et al. 2013; Moffitt et al. 2011). However, it has to be noted that those results and the reported effect sizes are under debate (e.g., Michaelson and Munakata 2020; Watts et al. 2018). First approaches to support children with lower DoG have been made e.g., by Murray et al. (2016) focusing on attention training, a metacognitive therapy technique, to improve children's DoG. In this auditory attention training by Wells (1990), participants were instructed to focus their attention e.g., on a particular sound and then switch to another sound (Murray et al., 2016). A subsequent study confirmed the positive effect of this attention training technique on DoG in children (Murray et al. 2018). Additionally, a circle time games intervention focusing on ritual participation in children was shown to have positive effects on children's executive function as well as children's DoG (Rybanska et al. 2018). In contrast to interventions focusing on cognitive factors to improve DoG in children, Michaelson and Munakata (2020) suggest interventions focusing on social factors such as supporting parents and educators to develop norms regarding DoG and to let children experience that they will actually receive the rewards they delay. This suggests that interventions aiming on the level of the parents' (and other caregivers'/educators') personality and related traits might be an especially promising approach. This could include both interventions supporting beneficial personality development, as well as targeting identified behaviors related to those personality traits.
To be able to define subgroups which benefit most of those programs, further research is needed to identify the contribution of these factors to the development of DoG. Additionally, it could be very beneficial to also involve parents in possible interventions to increase children's DoG. Therefore, it will be important to identify mediators of the relationship of parents' personality and children's DoG, e.g., specific parental behaviors, in order to be trained or at least be moved into the focus of parental attention. Our results indicate that not only the mother's, but also the father's role should be taken into account in such efforts. As specific parenting behavior like responsiveness, warmth, behavioral control, and autonomy support seems to be conducive to children's executive function, effortful control, and self-regulation (Bindman et al. 2015; Edwards 2015; Karreman et al. 2006; Kochanska et al. 2000), it might be beneficial to encourage these behaviors in parents in order to benefit DoG in their children.

In the present study, DoG operationalized as waiting time in minutes was associated negatively with maternal openness to experience and positively with maternal agreeableness in a sample of young children. Additionally, paternal agreeableness was positively associated with children's DoG. To our knowledge, this is the first study investigating maternal and paternal personality together in order to explain their relationship with children's DoG. Furthermore, based on this study, a direct relationship between paternal personality and children's DoG was observed for the first time, highlighting the importance of 
the father's role when assessing parental influence on the children's DoG. Further research is needed to understand the mechanisms underlying the demonstrated associations and therefore explain how maternal and paternal personality traits may contribute to children's DoG in a differential way. In the present cohort, future study waves will enable the investigation of the association of outcome measures such as school performance with DoG while assessing the influence of the parents' personality.

Acknowledgements We thank all parents and children for taking part in this study and our student employees and interns for their support with data acquisition and data entry. Furthermore, we would like to thank Prof. Dr. Manfred Laucht for his helpful advice.

Funding This work was supported by an Era-Net Neuron grant to M.D. and M.R., the German Federal Ministry of Education and Research (BMBF) through the Integrated Network IntegraMent (Integrated Understanding of Causes and Mechanisms in Mental Disorders), under the auspices of the e:Med Programme (grant 01ZX1614G to M.R.), through ERA-NET NEURON "Impact of Early life MetaBolic and psychosocial strEss on susceptibility to mental Disorders; from converging epigenetic signatures to novel targets for therapeutic intervention" (01EW1904 to M.R.) and by a grant of the Dietmar Hopp Foundation. The study was supported by the German Research Foundation (DFG; grant FOR2107; RI908/11-2 to M.R.; WI3429/3-2 to S.H.W.). T.S.S. received a scholarship provided by the University Outpatient Clinic for Psychotherapy, University of Koblenz-Landau, Landau, Germany. Open Access funding enabled and organized by Projekt DEAL.

\section{Compliance with Ethical Standards}

Conflict of Interest The authors declare no competing interests.

Ethical Approval All procedures performed in studies involving human participants were in accordance with the ethical standards of the institutional research committee (Ethics Committee of the Medical Faculty Mannheim of the University of Heidelberg, reference number 2014-550N-MA) and with the 1964 Helsinki declaration and its later amendments or comparable ethical standards.

Informed Consent Informed consent/assent was obtained from all individual participants included in the study.

Publisher's note Springer Nature remains neutral with regard to jurisdictional claims in published maps and institutional affiliations.

Open Access This article is licensed under a Creative Commons Attribution 4.0 International License, which permits use, sharing, adaptation, distribution and reproduction in any medium or format, as long as you give appropriate credit to the original author(s) and the source, provide a link to the Creative Commons license, and indicate if changes were made. The images or other third party material in this article are included in the article's Creative Commons license, unless indicated otherwise in a credit line to the material. If material is not included in the article's Creative Commons license and your intended use is not permitted by statutory regulation or exceeds the permitted use, you will need to obtain permission directly from the copyright holder. To view a copy of this license, visit http://creativecommons. org/licenses/by/4.0/.

\section{References}

Allemand, M., \& Martin, M. (2016). On Correlated Change in Personality. European Psychologist, 21(4), 237-253. https://doi.org/ 10.1027/1016-9040/a000256.

Anokhin, A. P., Grant, J. D., Mulligan, R. C., \& Heath, A. C. (2015). The genetics of impulsivity: evidence for the heritability of delay discounting. Biological Psychiatry, 77(10), 887-894. https://doi. org/10.1016/j.biopsych.2014.10.022.

Bandura, A. (1986). Social foundations of thought and action. Englewood Cliffs. NJ, 1986, 23-28.

Bindman, S. W., Pomerantz, E. M., \& Roisman, G. I. (2015). Do Children's Executive Functions Account for Associations Between Early Autonomy-Supportive Parenting and Achievement Through High School? Journal of Educational Psychology, 107(3), 756-770. https://doi.org/10.1037/edu0000017.

Drobetz, R., Maercker, A., Spiess, C. K., Wagner, G. G., \& Forstmeier, S. (2012). A Household Study of Self-Regulation in Children. Swiss Journal of Psychology, 71(4), 215-226. https:// doi.org/10.1024/1421-0185/a000090.

Duckworth, A. L., Tsukayama, E., \& Kirby, T. A. (2013). Is it really self-control? Examining the predictive power of the delay of gratification task. Personality \& Social Psychology Bulletin, 39 (7), 843-855. https://doi.org/10.1177/0146167213482589.

Edwards, A. (2015). The Relations Among Mothers' Personality, Parenting Behaviors, and Children's Regulation, Sympathy, and Prosocial Behavior [Doctoral dissertation, Arizona State University]. ASU Digital Repository. https://core.ac.uk/download/ pdf/79581773.pdf.

Eisenberg, N., Sadovsky, A., Spinrad, T. L., Fabes, R. A., Losoya, S. H., Valiente, C., Reiser, M., Cumberland, A., \& Shepard, S. A. (2005). The Relations of Problem Behavior to Children's Negative Emotionality, Effortful Control, and Impulsivity: Concurrent Relations and Prediction of Change. Developmental Psychology, 41(1), 193-211.

Escorial, S., \& Martin-Buro, C. (2012). The role of personality and intelligence in assortative mating. The Spanish Journal of Psychology, 15(2), 680-687. https://doi.org/10.5209/rev_sjop.2012. v15.n2.38879.

Fergusson, D. M., Boden, J. M., \& Horwood, L. J. (2013). Childhood self-control and adult outcomes: Results from a 30-year longitudinal study. Journal of the American Academy of Child and Adolescent Psychiatry, 52(7), 709. https://doi.org/10.1016/j.jaac. 2013.04.008.

Gottfried, A. E., Fleming, J. S., \& Gottfried, A. W. (1998). Role of Cognitively Stimulating Home Environment in Children's Academic Intrinsic Motivation: A Longitudinal Study. Child Development, 69(5), 1448-1460.

Houck, G. M., \& Lecuyer-Maus, E. A. (2004). Maternal limit setting during toddlerhood, delay of gratification, and behavior problems at age five. Infant Mental Health Journal, 25(1), 28-46. https:// doi.org/10.1002/imhj.10083.

Karreman, A., van Tuijl, C., van Aken, Marcel, A. G., \& Deković, M. (2006). Parenting and self-regulation in preschoolers: a metaanalysis. Infant and Child Development, 15(6), 561-579. https:// doi.org/10.1002/icd.478.

Kochanska, G., Murray, K. T., \& Harlan, E. T. (2000). Effortful Control in Early Childhood: Continuity and Change, Antecedents and Implications for Social Development. Developmental Psychology, 36(2), 220-232.

Komsi, N., Räikkönen, K., Heinonen, K., Pesonen, A.-K., Keskivaara, P., Järvenpää, A.-L., \& Strandberg, T. E. (2008). Transactional development of parent personality and child temperament. European Journal of Personality, 22(6), 553-573. https://doi.org/10. 1002/per.690. 
Körner, A., Geyer, M., Roth, M., Drapeau, M., Schmutzer, G., Albani, C., Schumann, S., \& Brähler, E. (2008). Persönlichkeitsdiagnostik mit dem NEO-Fünf-Faktoren-Inventar: Die 30-Item-Kurzversion (NEO-FFI-30). Psychother Psych Med, 58, 238-245.

Krueger, R. F., Caspi, A., Moffitt, T. E., White, J., \& StouthamerLoeber, M. (1996). Delay of Gratification, Psychopathology, and Personality: is Low Self-Control Specific to Externaiizing Problems? Journal of Personality, 64(1), 107-129.

Lewis, C., \& Lamb, M. E. (2003). Fathers' influences on children's development: the evidence from two-parent families. European Journal of Psychology of Education, 18(2), 211-228.

Li-Grining, C. P. (2007). Effortful control among low-income preschoolers in three cities: Stability, change, and individual differences. Developmental Psychology, 43(1), 208-221. https://doi. org/10.1037/0012-1649.43.1.208.

McCrae, R. R. (1987). Creativity, divergent thinking and opennes to experience. Journal of Personality and Social Psychology, 52(6), $1258-1265$.

McCrae, R. R., \& Costa, Jr, P. T. (1987). Validation of the Five-Factor Model of Personality Across Instruments and Observers. Journal of Personality and Social Psychology, 52(1), 81-90.

Michaelson, L. E., \& Munakata, Y. (2020). Same Data Set, Different Conclusions: Preschool Delay of Gratification Predicts Later Behavioral Outcomes in a Preregistered Study. Psychological Science, 31(2), 193-201. https://doi.org/10.1177/0956797619896270.

Mischel, W., \& Ebbesen, E. B. (1970). Attention in Delay of Gratification. Journal Ol Personality and Social Psychology, 16(2), 329-337.

Mischel, W., Ebbesen, E. B., \& Raskoff Zeiss, A. (1972). Cognitive and Attentional Mechanisms in Delay of Gratification. Journal oj Personality and Social Psychology, 21(2), 204-218.

Mischel, W., Shoda, Y., \& Peake, P. K. (1988). The nature of adolescent competencies predicted by preschool delay of gratification. Journal of Personality and Social Psychology, 54(4), 687-696. https://doi.org/10.1037//0022-3514.54.4.687.

Mischel, W., Shoda, Y., \& Rodriguez, M. L. (1989). Delay of Gratification in Children. Science, 244(4907), 933-938.

Mittal, R., Russell, B. S., Britner, P. A., \& Peake, P. K. (2012). Delay of Gratification in Two- and Three-Year-Olds: Associations with Attachment, Personality, and Temperament. Springer Science+Business Media, 479-489. https://doi.org/10.1007/ s10826-012-9600-6

Moffitt, T. E., Arseneault, L., Belsky, D., Dickson, N., Hancox, R. J., Harrington, H., Houts, R., Poulton, R., Roberts, B. W., Ross, S., Sears, M. R., Thomson, W. M., Caspi, A., \& Heckman, J. J. (2011). A gradient of childhood self-control predicts health, wealth, and public safety. Proceedings of the National Academy of Sciences of the United States of America, 108(7), 2693-2698.

Murray, J., Scott, H., Connolly, C., \& Wells, A. (2018). The Attention Training Technique improves Children's ability to delay gratification: a controlled comparison with progressive relaxation. Behaviour Research and Therapy, 104, 1-6. https://doi.org/10. 1016/j.brat.2018.02.003

Murray, J., Theakston, A., \& Wells, A. (2016). Can the attention training technique turn one marshmallow into two? Improving children's ability to delay gratification. Behaviour Research and Therapy, 77, 34-39. https://doi.org/10.1016/j.brat.2015.11.009.

Nigg, J. T., \& Hinshaw, S. P. (1998). Parent Personality Traits and Psychopathology Associated with Antisocial Behaviors in Childhood Attention-Deficit Hyperactivity Disorder. Journal of Child Psychology and Psychiatry, 39(2), 145-159. https://doi. org/10.1017/S0021963097001984.

Prinzie, P., Onghena, P., Hellinckx, W., Grietens, H., Ghesquière, P., \& Colpin, H. (2004). Parent and child personality characteristics as predictors of negative discipline and externalizing problem behaviour in children. European Journal of Personality, 18(2), 73-102. https://doi.org/10.1002/per.501.

Prinzie, P., Onghena, P., Hellinckx, W., Grietens, H., Ghesquière, P., \& Colpin, H. (2005). Direct and indirect relationships between parental personality and externalising behavior: The role of negative parenting. Psychologica Belgica, 45(2), 123-145.

Prinzie, P., Stams, Geert Jan, J. M., Dekovic, M., Reijntjes, A. H. A., \& Belsky, J. (2009). The relations between parents' Big Five personality factors and parenting: A meta-analytic review. Journal of Personality and Social Psychology, 97(2), 351-362. https://doi.org/10.1037/a0015823.

Rantanen, J., Metsäpelto, R.-L., Feldt, T., Pulkkinen, L., \& Kokko, K. (2007). Long-term stability in the Big Five personality traits in adulthood. Scandinavian Journal of Psychology, 48, 511-518. https://doi.org/10.1111/j.1467-9450.2007.00609.x.

Razza, R. A., \& Raymond, K. (2013). Associations among Maternal Behavior, Delay of Gratification, and School Readiness across the Early Childhood Years. Social Development, 22(1), 180-196. https://doi.org/10.1111/j.1467-9507.2012.00665.x.

Roberti, J. W. (2004). A review of behavioral and biological correlates of sensation seeking. Journal of Research in Personality, 38(3), 256-279. https://doi.org/10.1016/S0092-6566(03)00067-9.

Rybanska, V., McKay, R., Jong, J., \& Whitehouse, H. (2018). Rituals Improve Children's Ability to Delay Gratification. Child Development, 89(2), 349-359. https://doi.org/10.1111/ cdev.12762.

Sanchez-Roige, S., Fontanillas, P., Elson, S. L., Pandit, A., Schmidt, E. M., Foerster, J. R., Abecasis, G. R., Gray, J. C., Wit, H., de, Davis, L. K., MacKillop, J., \& Palmer, A. A. (2018). Genomewide association study of delay discounting in 23,217 adult research participants of European ancestry. Nature Neuroscience, 21(1), 16-18. https://doi.org/10.1038/s41593-017-0032-x.

Shoda, Y., Mischel, W., \& Peake, P. K. (1990). Predicting Adolescent Cognitive and Self-Regulatory Competencies From Preschool Delay of Gratification: Identifying Diagnostic Conditions. Developmental Psychology, 26(6), 978-986.

Silverman, I. W. (2003). Gender Differences in Delay of Gratification: a Meta-Analysis. Sex Roles, 49(9/10), 451-463.

Send, T. S., Gilles, M., Codd, V., Wolf, I., Bardtke, S., Streit, F., . . . Witt, S. H. (2017). Telomere Length in Newborns is Related to Maternal Stress During Pregnancy. Neuropsychopharmacology, 42(12), 2407-2413. https://doi.org/10.1038/npp.2017.73.

Send, T. S., Bardtke, S., Gilles, M., Wolf, I. A.-C., Sütterlin, M. W., Kirschbaum, C., . . . Deuschle, M. (2019). Stress reactivity in preschool-aged children: Evaluation of a social stress paradigm and investigation of the impact of prenatal maternal stress. Psychoneuroendocrinology, 101, 223-231. https://doi.org/10.1016/j. psyneuen.2018.11.002.

Watts, T. W., Duncan, G. J., \& Quan, H. (2018). Revisiting the Marshmallow Test: a Conceptual Replication Investigating Links Between Early Delay of Gratification and Later Outcomes. Psychological Science, 29(7), 1159-1177. https://doi.org/10.1177/ 0956797618761661.

Wells, A. (1990). Panic disorder in association with relaxation induced anxiety: an attentional training approach to treatment. Behavior Therapy, 21(3), 273-280.

Wolf, I. A.-C., Gilles, M., Peus, V., Scharnholz, B., Seibert, J., JennenSteinmetz, C., . . Laucht, M. (2017). Impact of prenatalstress on the dyadic behavior of mothers and their 6-month-old infants during a play situation: Role of different dimensions of stress. Journal of Neural Transmission, 124(10), 1251-1260. https://doi. org/10.1007/s00702-017-1770-3. 